\title{
PrEP awareness among men who have sex with men at higher risk for HIV in Brazil, Mexico, and Peru, 2018
}

\section{Ryan David Assaf ( $\nabla$ rassaf@ucla.edu )}

University of California Los Angeles Jonathan and Karin Fielding School of Public Health

\section{Kelika A. Konda}

Centro de Investigación Interdisciplinaria en Sexualidad Sida y Sociedad, UPCH, Lima, Peru

\section{Thiago S. Torres}

Instituto Nacional de Infectologia Evandro Chagas, Fundação Oswaldo Cruz (INI-Fiocruz), Rio de Janeiro, Brazil

\section{E. Hamid Vega-Ramirez}

Condesa \& Condesa-Iztapalapa Specialized Clinics, Mexico City, Mexico

\section{Oliver A. Elorreaga}

Centro de Investigación Interdisciplinaria en Sexualidad Sida y Sociedad, UPCH, Lima, Peru

\section{Dulce Diaz-Sosa}

National Institute of Psychiatry Ramon de la Fuente Muñiz, Mexico City, Mexico

\section{Steven D. Diaz}

Center for Prevention and Comprehensive Healthcare for HIV/AIDS of Mexico City, Mexico

\section{Cristina Pimenta}

Brazilian Ministry of Health, Brasília, Brazil

\section{Rebeca Robles}

National Institute of Psychiatry Ramon de la Fuente Muñiz, Mexico City, Mexico

\section{Maria Elena Medina-Mora}

National Institute of Psychiatry Ramon de la Fuente Muñiz, Mexico City, Mexico

\section{Beatriz Grinsztejn}

Instituto Nacional de Infectologia Evandro Chagas, Fundação Oswaldo Cruz (INI-Fiocruz), Rio de Janeiro, Brazil

\section{Carlos Caceres}

Centro de Investigación Interdisciplinaria en Sexualidad Sida y Sociedad, UPCH, Lima, Peru

\section{Valdilea G. Veloso}

Instituto Nacional de Infectologia Evandro Chagas, Fundação Oswaldo Cruz (INI-Fiocruz), Rio de Janeiro, Brazil

\section{Research}

Keywords: pre-exposure prophylaxis, men who have sex with men, awareness, prevention, human immunodeficiency virus, Latin America

Posted Date: December 30th, 2019

DOI: https://doi.org/10.21203/rs.2.19705/v1 
License: @ (i) This work is licensed under a Creative Commons Attribution 4.0 International License. Read Full License 


\section{Abstract}

\section{Introduction}

PrEP awareness in Latin America has been poorly characterized, with studies in Brazil, Mexico, and Peru highlighting low awareness. We assessed the association between higher risk of HIV infection, indicative of PrEP eligibility, and PrEP awareness among men who have sex with men (MSM) from these countries.

\section{Methods}

MSM were recruited to complete an online survey via advertisements on Facebook, Grindr, and Hornet from MarchJune 2018. Eligible individuals were cisgender MSM, $\geq 18$ years old, HIV negative or of unknown status, lived in these countries, and provided informed consent. Higher risk was defined using a CDC score indicating an increased risk of HIV infection and the suggested cutpoint of 10. We used Poisson regression models to calculate adjusted prevalence ratios (aPR) testing the association between higher risk and PrEP awareness; socio-demographics and other risk variables were considered potential confounders. Separate models were conducted for Brazil, Mexico, and Peru.

\section{Results}

After exclusion, 19,457 MSM were available for analysis. Overall PrEP awareness was 64.9\%, with those from Brazil reporting highest awareness (68.8\%), followed by Mexico (64.1\%), and Peru (46.6\%). In Brazil, 53.8\% were classified as higher risk for HIV, 51.9\% in Mexico, and 54.2\% in Peru. Higher risk for HIV was associated with PrEP awareness among those in Brazil (aPR 1.04, 95\% Cl 1.01, 1.06), but no association was seen in Mexico or Peru. Additionally, having more than high school education, high income, daily use of gay social networking (GSN) applications, and substance use were associated with PrEP awareness in each country.

\section{Conclusion}

Higher risk of HIV infection was associated with increased PrEP awareness in Brazil. However, this association was weak indicating that MSM at higher risk, who would benefit from PrEP, are often not aware of this prevention strategy. In the remaining countries, there was no association between risk and awareness, highlighting a disconnect between need and knowledge. As PrEP is introduced, awareness should increase, as in Brazil where PrEP has been available longer. Interventions to increase PrEP awareness are paramount to increase PrEP uptake and prevent HIV infections. GSN applications and social media could play an important role to achieve this goal.

\section{Introduction}

Human immunodeficiency virus (HIV) remains a global pandemic. In 2018, there were 37.9 million people living with HIV and 770,000 HIV-related deaths worldwide, with 2.2 million cases of HIV and 100,000 new infections in Latin America (1, 2). Brazil, Mexico, and Peru had an estimated 900,000, 230,000 and 79,000 HIV cases respectively in 2018 (3-5). However, gay, bisexual and other men who have sex with men (MSM) are disproportionally impacted with HIV in Latin America $(1,6-13)$ and are 33.3 times more likely to be infected with HIV compared to the general population (14). This risk for HIV may be an underestimate as MSM in Latin America continually face social stigmatization and may not seek HIV testing or treatment $(14,15)$. 
Although the global burden of HIV persists, oral pre-exposure prophylaxis (PrEP) for HIV with tenofovir and emtricitabine (TDF/FTC) is a safe and effective tool in biomedical interventions (16-21). When taken four to seven days a week, PrEP has been indicated to provide protection against HIV by more than 90\% (22). PrEP use has been recommended by the World Health Organization (WHO) in 2014 as an additional tool to prevent HIV among MSM and was revised in 2015 to include any high-risk population $(15,23,24)$.

Brazil became the first country in Latin America to include PrEP within its country's health system in 2018, making it freely available to populations at high risk for HIV infection such as MSM and transgender women (TGW) (25). Large scale PrEP implementation in Brazil, Mexico and Peru started in 2018 and is currently in progress (www.imprep.org) (26).

A prospective longitudinal demonstration project of PrEP in Brazil from 2014 to 2015 among MSM and TGW, showed that prior PrEP awareness was associated with PrEP uptake (adjusted odds ratio [aOR] 2.19, 95\% confidence interval $[\mathrm{CI}] 1.52,3.16)$; those who were eligible for the study, but choose not to enroll were younger and less educated (all p-values<0.05). It was concluded that efforts to raise awareness of PrEP and HIV risk perception among younger and less educated MSM and TGW need to be increased (27). Factors previously shown to be associated with PrEP awareness in Brazil included older age, more years of education, higher income, having more friends with the same sexual orientation, marijuana use, having an HIV positive partner, having more than 5 partners in the previous 6 months, and ever having an HIV test (28-30). In Peru, PrEP awareness was assessed in focus groups with Peruvian MSM, TGW, and female sex workers; respondents in all three groups indicated little to no knowledge or awareness of PrEP (31). Prior studies in Peru that assessed PrEP awareness and knowledge took place from 2008 to 2011(23, 31-33), preceding being proven efficacious and WHO's 2014 PrEP recommendation. PrEP awareness in Latin America was assessed in 2012 among residents in Brazil, Mexico, and Colombia; survey results showed overall $10.4 \%$ of the study population were aware of PrEP (34). However, most participants had a college education and were of middle to high income. Thus, the sample may not be representative of those who may have less access to care and thus less awareness of PrEP (34).

Although Brazil has some data (27-30), most of the countries in Latin America, including Mexico and Peru, have limited information about factors associated with awareness of PrEP. Overall, factors associated with awareness of PrEP in Latin America remains poorly characterized, and is limited in Brazil, Mexico, and Peru. Thus, there is a gap in our understanding of PrEP awareness in Latin America, especially as PrEP begins to become available. We have previously reported that awareness of PrEP among MSM was 68.8\% in Brazil, $64.1 \%$ in Mexico and $46.6 \%$ in Peru in 2018 (35).

\section{Methods}

\section{Study aims}

The objective of this analysis is to assess the association between MSM at higher risk for HIV and awareness of PrEP among those in Brazil, Mexico, and Peru. Additionally, we aim to assess which factors are associated with awareness of PrEP in these populations.

\section{Study design and population}

\section{Data collection}


Data collection consisted of a 10 to 15-minute anonymous web-based survey; those from Brazil responded to the survey in Portuguese via SurveyGizmo ${ }^{\circledR}$ and those from Mexico and Peru responded in Spanish via SurveyMonkey ${ }^{\circledR}$. No personally identifying information was collected. Participants answered questions on demographics, sexual behaviors, HIV testing and STI status, as well as awareness, willingness to use, and past or current use of PrEP.

\section{Variable definitions and categorization}

The primary outcome was the respondent's awareness of PrEP. For comparison, participants were dichotomized into those who indicated they were aware of PrEP and those who indicated they were not aware of PrEP. PrEP awareness in our survey was asked as "Have you ever heard of PrEP?".

Our exposure of interest was higher risk for HIV acquisition defined using the United States' Centers for Disease Control and Prevention's (CDC) MSM risk index score defined by the suggested cut-point of 10 for increased risk of HIV infection (36). Cocaine was used in addition to methamphetamine as methamphetamine use was virtually nonexistent in our study population $(29,30)$.

Other variables of interest included demographics, substance use, use of geosocial networking (GSN) applications (apps) to find sex partners, and binge drinking of alcohol and have been previously defined (35). Substance use in this analysis was defined as use of erectile dysfunction drugs, marijuana, or both erectile dysfunction drugs and marijuana in the last 6 months. Race/ethnicity was collected differently in Mexico compared to Brazil and Peru. For Mexico, race/ethnicity were two categories (white/other and indigenous), while race/ethnicity in Brazil and Peru consisted of four categories (white, black, mix, and other).

\section{Variable Selection and Statistical Analyses}

Demographic and variable distributions among the populations in each country were determined by descriptive analyses using frequencies, median, and interquartile range (IQR). Bivariate analyses used Pearson's chi-squared tests to compare participant characteristics, social behaviors and sexual behaviors with PrEP awareness. Bivariate and multivariable modeling was performed using generalized linear modeling (GLM) with Poisson regression and robust adjustment. Poisson regression with robust adjustment was used to obtain efficient results closest to the Mantel-Hansel prevalence ratio (37). Results are presented as prevalence ratios (PR), adjusted prevalence ratios (aPR) and 95\% confidence intervals (CI). Covariates were included in the model based on a priori knowledge and other factors found in the literature to be associated with PrEP awareness. Directed acyclic graphs (DAGs) were used to identify confounders and mediators (38). Age, education, race/ethnicity, income, use of GSN apps, substance use, and binge drinking were considered potential confounders. HIV testing was believed to be a mediator and was purposefully not included in the analysis as it could reduce the effect of the interest. Number of sex partners and number of HIV positive partners were considered confounders of the relationship between HIV risk and PrEP awareness; however, both variables were used in the CDC MSM risk index to create risk for HIV. Therefore, there would be collinearity between the exposure of interest and these two variables which may induce bias (39). Thus, these variables were not included in the models.

Separate multivariable models by country were constructed for Brazil, Mexico, and Peru. Each multivariable model consisted of the same variables. Due to the response rates per country, sample sizes between models were different. Education in the descriptive analyses was five categories (less than high school, high school, did not complete undergraduate, completed undergraduate, and postgraduate degree). However, respondents reporting less 
than high school education was too small for the multivariable analysis, especially for Peru. Consequently, less than high school and high school were collapsed. All analyses were conducted using STATA v.14 (STATA, College Station Texas, US).

\section{Results}

Of the 43,687 respondents who started the survey, 19,457 met the inclusion criteria described above and completed the survey to our predetermined cutoff point. The median age among study participants was 28 years old (IQR 2434). Most participants were from Brazil (58.4\%), followed by Mexico (30.5\%) and Peru (11.1\%). A large portion of respondents had a postsecondary degree (59.9\%) and only a few did not complete high school (1.5\%). Most respondents identified having middle $(43.1 \%)$ or low $(39.6 \%)$ income.

Overall awareness of PrEP was $64.9 \%$ with $3.8 \%$ of respondents self-reporting ever use of PrEP. Overall, the risk of participants based on the CDC's risk index indicated that $53.3 \%$ of the population would be at higher risk of HIV, but only $24.7 \%$ perceived themselves at moderate risk and $9.6 \%$ at higher risk. In Brazil, 53.8\% of respondents were classified as being at higher risk for HIV, 51.9\% in Mexico, and 54.2\% in Peru (data not shown).

Those from Brazil and Mexico who were 31-35 years of age reported the highest awareness of PrEP (75.4\% and $57.8 \%$ respectively). However, in Peru, those who were 36 years or older had the highest awareness (57.8\%). Respondents who reported their race as white in Brazil and Peru reported highest awareness of PrEP $(71.6 \%$ and $52.2 \%$, respectively). Among the three countries, those who reported higher income also reported higher awareness of PrEP in Brazil (80.6\%), Mexico (79.3\%), and Peru (70.2\%). Respondents who reported daily use of GSN apps reported higher awareness of PrEP in Brazil (70.5\%), Mexico (66.7\%), and Peru (52.5\%). Finally, respondents who reported use of both erectile dysfunction drugs and marijuana reported higher awareness of PrEP, $87.1 \%$ in Brazil, $85.1 \%$ in Mexico, and $75.9 \%$ in Peru (Table 1).

Risk for HIV, age, race/ethnicity, education, income, use of GSN apps, binge drinking, and substance use were associated with PrEP awareness in the bivariate models among those in Brazil and those in Mexico $(p-v a l u e s<0.05)$ (Table 2, Table 3). In Peru, age, race/ethnicity, education, income, GSN apps, and substance use were associated with PrEP awareness in the bivariate models ( $p$-value <0.05) (Table 4).

In the multivariable models, higher risk for HIV was associated with PrEP awareness in Brazil compared to those who were lower risk for HIV, aPR 1.04 (95\% Cl 1.01, 1.06) (Table2). However, in Mexico and Peru, higher risk for HIV was not associated with PrEP awareness, aPR 1.02 (95\% Cl 0.98, 1.06) and aPR 0.97 (95\% Cl 0.88, 1.07), respectively (Table 3, Table 4). In Brazil and Peru, being 25-30 years of age was associated with increased PR of PrEP awareness compared to those who were 18-24 years of age. Additionally, in Brazil, being 31-35 years of age was positively associated with PrEP awareness compared to those who were 18-24 years of age (Table 2, Table 4). In Brazil and Mexico, completing undergraduate, completed undergraduate, and having a postgraduate degree were all associated with increased PR of PrEP awareness compared to those with a high school degree or less (Table 2, Table 3). In all three countries, being of higher income was positively associated with PrEP awareness, while low income was negatively associated with PrEP awareness compared to having middle income (Table 2-4). Daily use of GSN apps to find sex partners among those from Brazil was positively associated with PrEP awareness compared to those who sometimes used GSN apps (Table 2). In Mexico and Peru, never use of GSN apps to find sex partners was negatively associated with PrEP awareness compared to those who sometimes used GSN apps

(Table 3, Table 4). In Peru, binge drinking was negatively associated with PrEP awareness compared to those who 
did not binge drink (Table 4). Finally, in all three countries, those who used marijuana only and those who used both marijuana and erectile dysfunction drugs were positively associated with PrEP awareness compared to those who did not use either. In addition, those in Brazil and Mexico who reported erectile dysfunction drugs use only were associated with an increased PR of PrEP awareness compared to those who did not use either marijuana or erectile dysfunction drugs (Table 2-4).

\section{Discussion}

Our study highlights the association with risk for HIV among MSM and PrEP awareness prior to PrEP being widely available in Brazil and before large scale PrEP implementation in select regions of Mexico and Peru. PrEP awareness was highest in Brazil; those at higher risk for HIV were more aware of PrEP. However, the point estimate for higher risk MSM compared to lower risk MSM in Brazil was small (aPR 1.04). In Mexico and Peru, higher risk for HIV was not associated with PrEP awareness. Overall, the findings from this study are troublesome, as those who are at higher risk for HIV and most likely in need of PrEP, may not be aware. Therefore, if awareness in these groups are low, it is likely that PrEP uptake and thus, prevention of new HIV cases with PrEP will be lower. It is essential to focus prevention efforts to target these populations who may be at highest risk for HIV and where the epidemic may continue.

It is likely that the association of higher risk for HIV and PrEP awareness between these three countries reflects the duration of PrEP availability and accessibility of PrEP in each. Brazil has had PrEP for the longest time and has made it available at the national level, whereas Mexico and Peru have only recently implemented PrEP in a few sites $(25,26)$. These differences may explain the greater overall percentage of awareness in Brazil in comparison to Mexico and Peru. The findings from this study show that PrEP implementation in the health systems of these countries and the information of PrEP's availability need to be further disseminated to increase levels of awareness. It is predicated that as PrEP implementation in these three countries continues, awareness of PrEP will also increase. As seen in previous studies, willingness to use PrEP is strongly associated with awareness $(27-29,35)$. Therefore, focus on increasing awareness of PrEP is an important first step in targeting its uptake and use.

This study contributes to important findings about variables that are associated with PrEP awareness. PrEP awareness has been previously shown to be associated with older age, higher education, and higher income among those from Brazil (28-30). These findings held true in our study. PrEP awareness was associated with older age in Brazil and Peru. In Brazil and Mexico, higher than high school education was positively associated with PrEP awareness. Furthermore, higher income was associated with increased PR of PrEP awareness, while lower income was negatively associated with PrEP awareness in the three countries. This association highlights that those of higher education or higher income may be receiving or have access to information about PrEP, but those of lower education or lower income may not. This is of concern because those of lower income may have less access to health services compared to those who are of higher income (34). Further, risk for HIV among those of lower income may be as high or higher compared to those of higher income. This population, in addition to higher risk individuals, is one in which PrEP knowledge and service dissemination may be highly beneficial. This may also be true for those with lower education. Additionally, those of lower education may have less access to sexual health education and thus less awareness of PrEP as seen in a population of black MSM in New York City, New York, United States (40). Therefore, future interventions should focus on reaching these groups $(27,40)$.

Other variables associated with PrEP awareness in our study population included use of GSN apps and substance use. Daily use of GSN apps to find sex partners was positively associated with PrEP awareness in Brazil. Agreeing 
with other literature, this finding shows that GSN applications may be used as a platform to spread awareness of PrEP and education $(29,41,42)$. Exposure to PrEP information in GSN applications may occur through advertisements or in users' profiles where they indicate PrEP use $(41,43)$. Further, never use of GSN applications showed a negative association with PrEP awareness in Mexico and Peru. Thus, individuals who never use GSN applications may be less exposed to PrEP information while those who use GSN applications daily are more exposed to information. Use of GSN applications may also be a proxy for social factors that would increase exposure to PrEP information (41). Substance use (marijuana use only, erectile dysfunction drugs use only, and use of both) was positively associated with PrEP awareness in all three countries. Use of these substances may reflect proxy associations with PrEP awareness due to social and behavioral factors other than just using the substances. As shown previously in Brazil, having more than 5 partners in the previous 6 months, having more friends with the same sexual orientation, and marijuana use is associated with PrEP awareness (30). Erectile dysfunction drugs use is suspected to be used in junction with sex and may increase the number of sex partners one has. Thus, it is possible that one's exposure to others (which may include friends/partners with the same sexual orientation) who may know about or use PrEP, increases their awareness of PrEP. Similarly, marijuana may be used with others (friends with the same sexual orientation), which may increase the possibility of exposure to PrEP information.

\section{Strengths:}

This study was made available to individuals on social media platforms such as Facebook ${ }^{\odot}$ and GSN apps such as Grindr $^{\odot}$ and Hornet ${ }^{\odot}$. Participants that came across the advertisements were not incentivized to participate in the survey. Over 40,000 participants started the survey and 19,457 were included in the analyses. Information bias, specifically social desirability bias, may be limited because the surveys were anonymous and filled out at the individuals' will. No identifying information was collected; therefore, the effect of stigma and other social factors may be reduced. Finally, we were able to obtain large sample sizes from all three countries throughout the different regions of the countries. The distribution of higher risk individuals reflected the regions where HIV is most prevalent in these countries.

\section{Limitations:}

This study has some limitations that must be addressed. The final sample size for Brazil, Mexico, and Peru was $11,325,5,921$, and 2,150 for descriptive analyses respectively, but were slightly reduced in the multivariable models because of missing data. Brazil retained $95 \%$ of respondents, while Mexico retained $88 \%$, and Peru retained $85 \%$. Respondents had the ability to state "I don't know, or I don't want to answer" to questions, which was considered missing in the analysis. Differences in missing data by country may induce selection bias related to exposure and confounder information. Second, all information collected on individuals was self-reported. We did not have access to medical records or other sources of data to cross check for misclassification. Recall bias may also impact the results as respondents were asked about exposures from 3 months, 6 months, and 12 months from the time of the survey. Third, selection bias may also exist in this study due to convenient sampling. The study design aimed to limit selection bias by making the study available to participants in the three countries on multiple online forums and by allowing the survey to be disseminated to peers who may have not had access to these online sites. However, respondents needed access to a smartphone or computer and internet access thus, missing those without access. Moreover, education and income reflected distributions similar to those in Brazil, Mexico, and Peru, but higher income and higher education seemed to be overrepresented. Finally, there were some differences in how questions were posed between the countries. Specifically, income in Brazil was asked as family income, while 
income in Mexico and Peru was asked as individual income. Therefore, conclusions of income in Brazil are different than those for Mexico and Peru.

\section{Conclusion}

Awareness of PrEP among those at risk for HIV is an important first step in increasing PrEP uptake and use in areas where PrEP is available. This study showed those who are at higher risk for HIV may be more aware of PrEP in Brazil, while limited results could be concluded for Mexico and Peru. This finding may reflect the availability of PrEP in each of these countries at the time of the survey. As PrEP accessibility increases in Mexico and Peru, it is predicted that awareness of PrEP will rise similar to that seen in Brazil. Future work should focus on reaching those populations at higher risk for HIV. Income and education were seen in this study to be associated with awareness of PrEP. However, it is essential to identify ways to increase knowledge and awareness of PrEP among those of lower income and lower education where PrEP awareness is lowest. Finally, the use of GSN apps can continue to be a useful platform to spread information about PrEP and its availability in these three countries. PrEP can be a useful tool in ending the epidemic in Latin America, but more work is needed for PrEP interventions to reach the populations who can benefit from this intervention.

\section{Declarations}

\section{Ethics approval and consent to participate}

All respondents provided digital informed consent prior to initiating the survey.

\section{Consent for publication}

Not applicable.

\section{Availability of data and materials}

The data that support the finding of this study are available from the ImPrEP study group (www.imprep.org), but restrictions apply to the availability of these data, which were used under license for the current study, and so are not publicly available. Data are however available from the authors upon reasonable request and with permission of ImPrEP study group.

\section{Competing Interests}

The authors do not have any competing interests to disclose, real or perceived.

\section{Funding}

Not applicable

\section{Author's Contributions}

RDA, TST, KAK, and EHVR did the literature search and developed the survey. RDA, KAK, and OAE analyzed the data and generated the tables and figures. RDA, KAK, TST, and EHVR interpreted the data. RDA, KAK, TST, and EHVR drafted the manuscript. DDS, STD, CP, RR, MEMM, BG, CC, and VGV revised the manuscript and contributed intellectually. 
Conflicts of interest: None declared

\section{Acknowledgments}

This project was made possible, thanks to Unitaid's funding and support. Unitaid accelerates access to innovative health products and lays the foundations for their scale-up by countries and partners. Unitaid is a hosted partnership of the WHO. We would like to thank the Ministries of Health of Brazil, Mexico, and Peru.

\section{Abbreviations}

HIV: Human immunodeficiency virus

MSM: Men who have sex with men

PrEP: Pre-exposure prophylaxis

TDF/FTC: Tenofovir and emtricitabine

WHO: World Health Organization

TGW: Transgender women

aOR: Adjusted odds ratio

Cl: Confidence interval

CDC: Centers for Disease Control and Prevention

GSN: Geosocial networking

IQR: Interquartile range

GLM: Generalized linear modeling

PR: Prevalence ratios

aPR: Adjusted prevalence ratios

DAGs: Directed acyclic graphs

\section{References}

1. AVERT. HIV AND AIDS IN LATIN AMERICA THE CARIBBEAN REGIONAL OVERVIEW 2019 [updated August 20, 2019. Available from: https://www.avert.org/professionals/hiv-around-world/latin-america/overview.

2. World Health Organization. Global Health Observatory (GHO) data: HIV/AIDS 2019 [Available from: https://www.who.int/gho/hiv/en/.

3. UNAIDS. Country Factsheets: BRAZIL 2019 [Available from:

https://www.unaids.org/en/regionscountries/countries/brazil. 
4. UNAIDS. Country Factsheets: MEXICO 2019 [Available from:

http://www.unaids.org/en/regionscountries/countries/mexico.

5. UNAIDS. Country Factsheets: PERU 2019 [Available from:

http://www.unaids.org/en/regionscountries/countries/peru.

6. Bristow CC, Kojima N, Lee SJ, Leon SR, Ramos LB, Konda KA, et al. HIV and syphilis testing preferences among men who have sex with men and among transgender women in Lima, Peru. PLoS One. 2018;13(10):e0206204.

7. Galea JT, Baruch R, Brown B. PrEP Ya! Latin America wants PrEP, and Brazil leads the way. Lancet HIV. 2018;5(3):e110-e2.

8. Garcia PJ, Bayer A, Carcamo CP. The changing face of HIV in Latin America and the Caribbean. Curr HIV/AIDS Rep. 2014;11(2):146-57.

9. Grangeiro A, Escuder MM, Castilho EA. Magnitude and trend of the AIDS epidemic in Brazilian cities, from 2002 to 2006. Rev Saude Publica. 2010;44(3):430-40.

10. Konda KA, Castillo R, Leon SR, Silva-Santisteban A, Salazar X, Klausner JD, et al. HIV Status Communication with Sex Partners and Associated Factors Among High-Risk MSM and Transgender Women in Lima, Peru. AIDS Behav. 2017;21(1):152-62.

11. Silva-Santisteban A, Raymond HF, Salazar X, Villayzan J, Leon S, McFarland W, et al. Understanding the HIV/AIDS epidemic in transgender women of Lima, Peru: results from a sero-epidemiologic study using respondent driven sampling. AIDS Behav. 2012;16(4):872-81.

12. UNAIDS. THE GAP REPORT. Geneva, Switzerland: UNAIDS; 2014.

13. Luz PM, Veloso VG, Grinsztejn B. The HIV epidemic in Latin America: accomplishments and challenges on treatment and prevention. Curr Opin HIV AIDS. 2019;14(5):366-73.

14. Beyrer C, Baral SD, Walker D, Wirtz AL, Johns B, Sifakis F. The expanding epidemics of HIV type 1 among men who have sex with men in low- and middle-income countries: diversity and consistency. Epidemiol Rev. 2010;32:137-51.

15. Ravasi G, Grinsztejn B, Baruch R, Guanira JV, Luque R, Caceres CF, et al. Towards a fair consideration of PrEP as part of combination HIV prevention in Latin America. J Int AIDS Soc. 2016;19(7(Suppl 6)):21113.

16. Grant RM, Lama JR, Anderson PL, McMahan V, Liu AY, Vargas L, et al. Preexposure chemoprophylaxis for HIV prevention in men who have sex with men. N Engl J Med. 2010;363(27):2587-99.

17. McCormack S, Dunn DT, Desai M, Dolling DI, Gafos M, Gilson R, et al. Pre-exposure prophylaxis to prevent the acquisition of HIV-1 infection (PROUD): effectiveness results from the pilot phase of a pragmatic open-label randomised trial. Lancet. 2016;387(10013):53-60.

18. Molina JM, Capitant C, Spire B, Pialoux G, Cotte L, Charreau I, et al. On-Demand Preexposure Prophylaxis in Men at High Risk for HIV-1 Infection. N Engl J Med. 2015;373(23):2237-46.

19. Thigpen MC, Kebaabetswe PM, Paxton LA, Smith DK, Rose CE, Segolodi TM, et al. Antiretroviral preexposure prophylaxis for heterosexual HIV transmission in Botswana. N Engl J Med. 2012;367(5):423-34.

20. Psaros C, Haberer JE, Katabira E, Ronald A, Tumwesigye E, Campbell JD, et al. An intervention to support HIV preexposure prophylaxis adherence in HIV-serodiscordant couples in Uganda. J Acquir Immune Defic Syndr. 2014;66(5):522-9.

21. Baeten JM, Donnell D, Ndase P, Mugo NR, Campbell JD, Wangisi J, et al. Antiretroviral prophylaxis for HIV prevention in heterosexual men and women. N Engl J Med. 2012;367(5):399-410.

Page $11 / 20$ 
22. Grant RM, Anderson PL, McMahan V, Liu A, Amico KR, Mehrotra M, et al. Uptake of pre-exposure prophylaxis, sexual practices, and HIV incidence in men and transgender women who have sex with men: a cohort study. Lancet Infect Dis. 2014;14(9):820-9.

23. World Health Organization. Policy brief on oral pre-exposure prophylaxis of HIV infection (PrEP). 2015.

24. World Health Organization. Pre-exposure prophylaxis 2018 [Available from: https://www.who.int/hiv/topics/prep/en/.

25. Ministério da Saúde. Ministé rio da Sau’de publica protocolo para utilizac,ão da PrEP Ministério da Saúde2017 [updated May 29, 2017. Available from: http://www.saude.gov.br/noticias/agencia-saude/28555ministerio-da-saude-publica-protocolo-parautilizacao-da-prep.

26. Veloso VG; Vega-Ramirez EH HB, Konda KA, Bautista-Arredondo S, Guanira JV, Leyva-Flores R, Pimenta C, Benedetti M, Luz PM, Leite IC, Moreira RI, Grinsztejn B, Caceres CF. Safety, early continuation and adherence of same day PrEP initiation among MSM and TGW in Brazil, Mexico and Peru: the ImPrEP Study. International AIDS Society; Mexico City, Mexico2019.

27. Hoagland B, Moreira RI, De Boni RB, Kallas EG, Madruga JV, Vasconcelos R, et al. High pre-exposure prophylaxis uptake and early adherence among men who have sex with men and transgender women at risk for HIV Infection: the PrEP Brasil demonstration project. J Int AIDS Soc. 2017;20(1):21472.

28. Hoagland B, De Boni RB, Moreira RI, Madruga JV, Kallas EG, Goulart SP, et al. Awareness and Willingness to Use Pre-exposure Prophylaxis (PrEP) Among Men Who Have Sex with Men and Transgender Women in Brazil. AIDS Behav. 2017;21(5):1278-87.

29. Torres TS, De Boni RB, de Vasconcellos MT, Luz PM, Hoagland B, Moreira RI, et al. Awareness of Prevention Strategies and Willingness to Use Preexposure Prophylaxis in Brazilian Men Who Have Sex With Men Using Apps for Sexual Encounters: Online Cross-Sectional Study. JMIR Public Health Surveill. 2018;4(1):e11.

30. Torres TS, Luz PM, De Boni RB, de Vasconcellos MTL, Hoagland B, Garner A, et al. Factors associated with PrEP awareness according to age and willingness to use HIV prevention technologies: the 2017 online survey among MSM in Brazil(). AIDS Care. 2019:1-10.

31. Galea JT, Kinsler JJ, Salazar X, Lee SJ, Giron M, Sayles JN, et al. Acceptability of pre-exposure prophylaxis as an HIV prevention strategy: barriers and facilitators to pre-exposure prophylaxis uptake among at-risk Peruvian populations. Int J STD AIDS. 2011;22(5):256-62.

32. Peinado J, Lama JR, Galea JT, Segura P, Casapia M, Ortiz A, et al. Acceptability of oral versus rectal HIV preexposure prophylaxis among men who have sex with men and transgender women in Peru. J Int Assoc Provid AIDS Care. 2013;12(4):278-83.

33. Eisingerich AB, Wheelock A, Gomez GB, Garnett GP, Dybul MR, Piot PK. Attitudes and acceptance of oral and parenteral HIV preexposure prophylaxis among potential user groups: a multinational study. PLoS One. 2012;7(1):e28238.

34. Edeza A, Galarraga O, Novak D, Mayer K, Rosenberger J, Mimiaga M, et al. The role of sexual risk behaviors on PrEP awareness and interest among men who have sex with men in Latin America. Int J STD AIDS. 2019;30(6):542-9.

35. Torres T, Konda, K, Vega-Ramirez, EH, Elorreaga Reyes, OA, Diaz-Sosa, D, Hoagland, B, Diaz, S, Pimenta, C, Bennedeti, M, Lopez-Gatell, H, Robles-Garcia, R, Grinsztejn, B, Caceres, C, Veloso, VG Factors associated with willingness to use Pre-exposure prophylaxis in Brazil, Mexico and Peru: an online survey among men who have sex with men. JMIR Public Health Surveill. 2019;in press. 
36. Centers for Disease Control and Prevention. Pre-exposure Prophylaxis for the Prevention of HIV Infection in the United States - 2017 Update Clinical Providers' Supplement 2017.

37. Barros AJ, Hirakata VN. Alternatives for logistic regression in cross-sectional studies: an empirical comparison of models that directly estimate the prevalence ratio. BMC Med Res Methodol. 2003;3:21.

38. Greenland S, Pearl J, Robins JM. Causal diagrams for epidemiologic research. Epidemiology. 1999;10(1):37-48.

39. Harrell FE. Regression Modeling Strategies: With Applications to Linear Models, Logistic Regression, and Survival Analysis. 1 ed. New York: Springer-Verlag New York; 2001. 572 p.

40. Garnett M, Hirsch-Moverman Y, Franks J, Hayes-Larson E, El-Sadr WM, Mannheimer S. Limited awareness of pre-exposure prophylaxis among black men who have sex with men and transgender women in New York city. AIDS Care. 2018;30(1):9-17.

41. Macapagal K, Kraus A, Korpak AK, Jozsa K, Moskowitz DA. PrEP Awareness, Uptake, Barriers, and Correlates Among Adolescents Assigned Male at Birth Who Have Sex with Males in the U.S. Arch Sex Behav. 2019.

42. Holloway IW, Tan D, Gildner JL, Beougher SC, Pulsipher C, Montoya JA, et al. Facilitators and Barriers to PreExposure Prophylaxis Willingness Among Young Men Who Have Sex with Men Who Use Geosocial Networking Applications in California. AIDS Patient Care STDS. 2017;31(12):517-27.

43. Newcomb ME, Mongrella MC, Weis B, McMillen SJ, Mustanski B. Partner Disclosure of PrEP Use and Undetectable Viral Load on Geosocial Networking Apps: Frequency of Disclosure and Decisions About Condomless Sex. J Acquir Immune Defic Syndr. 2016;71(2):200-6.

\section{Tables}


Table 1: Demographics and behaviors among respondents aware of PrEP: Brazil, Mexico, Peru (N= 19,457) April, 2018

Brazil $(\mathrm{N}=7,794 / 11,325) \quad$ Mexico $(\mathrm{N}=3,796 / 5,921) \quad$ Peru $(\mathrm{N}=1,002 / 2,150)$

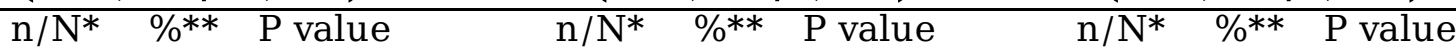

PrEP

$\begin{array}{lllllllllll}\text { Awareness }(\mathrm{N}) & 7,794 & 68.8 & -- & 3796 & 64.1 & -- & 1,002 & 46.6 & --\end{array}$

\section{Sociodemographic}

Characteristics

Age Category

$\begin{array}{rrr}36+ & 1,975 / 7,794 \\ 31-35 & 1,495 / 7,794 \\ 25-30 & 2,381 / 7,794 \\ 18-24 & 1,942 / 7,794\end{array}$

\begin{tabular}{|c|c|c|}
\hline & & \\
\hline 71.3 & $776 / 3796$ & 65.9 \\
\hline 75.4 & $679 / 3796$ & 70.3 \\
\hline 70.7 & $1,365 / 3796$ & 67.7 \\
\hline 60.7 & $976 / 3796$ & 55.4 \\
\hline
\end{tabular}

$\begin{array}{ll}171 / 1,002 & 57.8 \\ 134 / 1,002 & 52.6 \\ 370 / 1,002 & 51.9 \\ 327 / 1,002 & 36.9\end{array}$

$<0.001$

Race/Ethnicity

(Brazil \& Peru)

White

Black

$<0.001$

$\begin{array}{lll} & & -1 \\ -- & - \\ -- & - \\ -- & - \\ - & - \\ - & -\end{array}$

\begin{tabular}{l} 
\\
-- \\
\hline- \\
\hline- \\
--
\end{tabular}

$--$

cMix 2,290/7,794 65.1

dOther

Race/Ethnicity

$110 / 7,794 \quad 65.9$

$-$

(Mexico Only)

White/Other Indigenous

Education

Postgraduate Completed

undergraduate Did not complete

undergraduate Completed

high school

Less than high

$\begin{array}{lll}-1 & -1 \\ -- & - \\ -- & -\end{array}$

$-$

$\begin{array}{ccc} & 3,717 / 3796 & 64.4 \\ -\quad & 56 / 3796 & 50.0\end{array}$

$2,259 / 7,794 \quad 79.6$

$<0.001$

$2,939 / 7,794 \quad 72.9$

$706 / 3796$

78.5

$1,830 / 3796 \quad 69.6$

0.002

$478 / 7,794 \quad 62.8$

$1,219 / 3796 \quad 54.5$

$185 / 1,002$

35.7

$1,957 / 7,794 \quad 58.3$

$20 / 3796$

22.0

$165 / 1,002 \quad 36.6$

school $102 / 7,794 \quad 42.9$

Income

High $\quad 1,232 / 7,794 \quad 80.6$

Middle

Low

\section{Behaviors and}

HIV Testing

GSN Apps for

Sex

Daily

Sometimes

Never

$3,473 / 7,794$

$3,089 / 7,794$

74.1

60.5

$11 / 3796 \quad 27.5$

$1,124 / 3796 \quad 79.3$

$1,544 / 3796 \quad 64.5$

$821 / 3796 \quad 53.3$
$151 / 1,002 \quad 63.7$

$487 / 1,002 \quad 53.8$

$1 / 1,002 \quad 12.5$

$<0.001$

$191 / 1,002 \quad 70.2$

$448 / 1,002 \quad 47.4$

$259 / 1,002 \quad 36.6$

$4,315 / 7,794 \quad 70.5$

$<0.001$

$2,983 / 7,794 \quad 68.3$

68.3
59.8

$\begin{array}{ccc} & & <0.001 \\ 1,441 / 3796 & 66.7 & \\ 2,118 / 3796 & 63.6 & \\ 237 / 3796 & 55.4 & \end{array}$

$212 / 1,002$

$11 / 1,002$

$719 / 1,002 \quad 46.1$

$30 / 1,002 \quad 46.2$

0.008

$$
<0.001
$$

${ }^{\text {a Binge }}$

Drinking

Yes $5,422 / 7,794 \quad 69.9$

$<0.001$

$\begin{array}{lll} & & <0.001 \\ 372 / 1,002 & 52.5 & \\ 491 / 1,002 & 47.8 & \\ 139 / 1,002 & 33.6\end{array}$

asubstance

No $2,372 / 7,794 \quad 66.4$

$2,670 / 3796 \quad 65.3$

0.005

0.3

use

Erectile $505 / 7,794 \quad 76.8$

$<0.001$

$1,105 / 3796$

61.5

$694 / 1,002 \quad 45.9$

$293 / 1,002 \quad 48.3$

dysfunction

$280 / 3796 \quad 74.3$

$<0.001$

$34 / 1,002 \quad 55.7$

$<0.001$ 
use only

Marijuana use

only

$1,855 / 7,794 \quad 74.1$

$820 / 3796 \quad 71.9$

$246 / 1,002 \quad 55.9$

Marijuana and erectile dysfunction

use

$344 / 7,794 \quad 87.1$

$194 / 3796 \quad 85.1$

$22 / 1,002 \quad 75.9$

No use $5,090 / 7,794 \quad 65.5$

$2,502 / 3796 \quad 59.9$

$700 / 1,002 \quad 43.2$

\section{Sexual}

Behaviors and

Risk

${ }^{b}$ Perceived

Risk

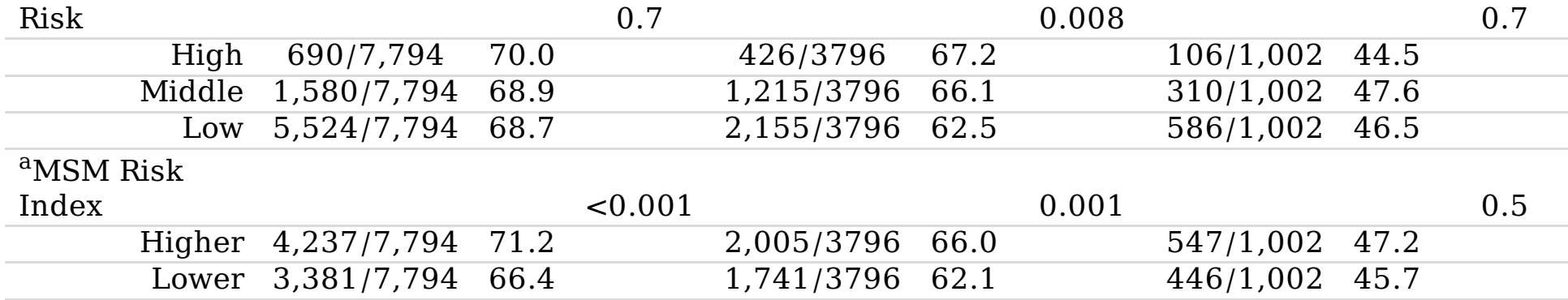

0.7

0.008

0.7

\footnotetext{
Abbreviations. MSM=Men who have Sex with Men; PrEP= Pre-Exposure Prophylaxis; HIV=Human Immunodeficiency Virus; GSN= Gay Social Networking

*May not add to total

because of missing data

** Percentages are indicators of those aware to those not

aware in that category

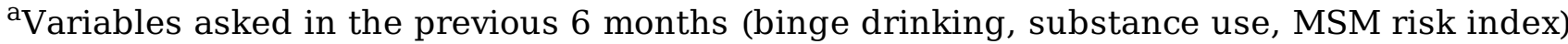

bVariables asked in the previous 12 months (perceived risk)

"Mix race/ethnicity included respondents who stated their race/ethnicity as "mestizo"

dOther race/ethnicity included respondents who stated their race/ethnicity was other
} 
Table 2: PrEP awareness among MSM in Brazil, crude and adjusted prevalence ratios $(n=11,325)$ April, 2018

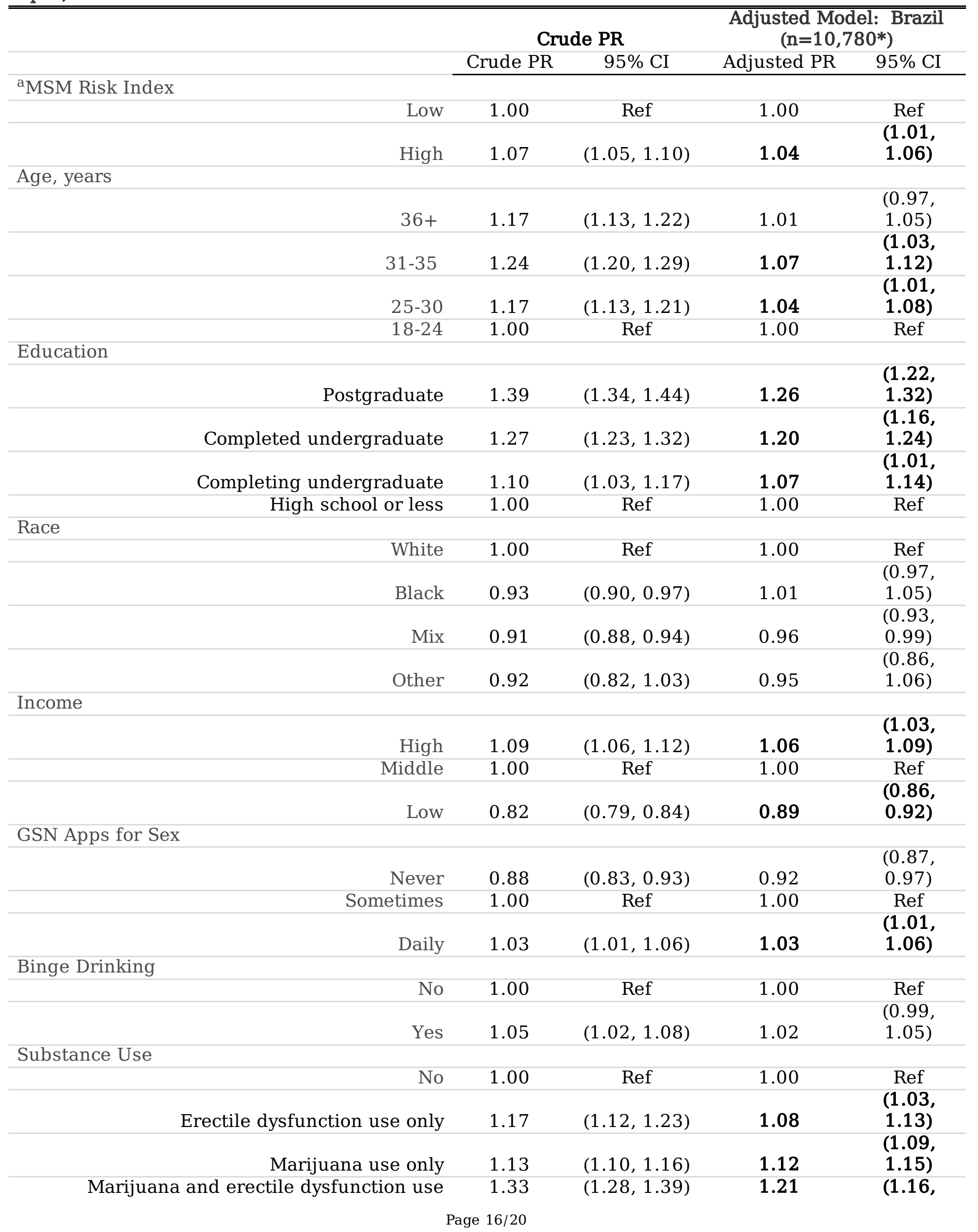


Abbreviations. PrEP= Pre-Exposure Prophylaxis; MSM=Men who have Sex with Men; HIV=Human Immunodeficiency Virus; PR= Prevalence ratios; GSN= Gay Social Networking

* May not add to total because of missing data

aAdjusted for: age, education, race/ethnicity, income, GSN apps for sex,

binge drinking, substance use

Table 3: PrEP awareness among MSM in Mexico, crude and adjusted prevalence ratios $(n=5,921)$ April, 2018

Adjusted Model: Mexico

Crude PR $(n=5,220 *)$

Adjusted

\section{${ }^{\mathrm{a} M S M}$ Risk Index}

Crude PR

$95 \%$ CI

PR

$95 \% \mathrm{CI}$

$\begin{array}{rcccc}\text { Low } & 1.00 & \text { Ref } & 1.00 & \text { Ref } \\ \text { High } & 1.06 & (1.02,1.11) & 1.02 & (0.98,1.06)\end{array}$

Age, years

$\begin{array}{cc}36+ & 1.19 \\ 31-35 & 1.27 \\ 25-30 & 1.22 \\ 18-24 & 1.00\end{array}$

$(1.12,1.26)$

0.95

$(0.88,1.02)$

$(1.20,1.35)$

1.04

$(1.16,1.29)$

1.05

Ref

1.00

$(0.97,1.11)$

$(0.99,1.11)$

Ref

\section{Education}

Postgraduate

Completed undergraduate Completing undergraduate High school or less

Race (Mexico only)

3.32
2.94
2.30
1.00

1.00

0.78
$(2.44,4.52)$

$(2.16,4.00)$

$(1.69,3.14)$

Ref

2.86

2.64

2.23

1.00

$(2.06,3.97)$

$(1.91,3.67)$

$(1.61,3.10)$

Ref

$\begin{array}{ccccc}\text { White/other } & 1.00 & \text { Ref } & 1 & \text { Ref } \\ \text { Indigenous } & 0.78 & (0.64,0.94) & 0.87 & (0.73,1.04)\end{array}$

Income

$\begin{array}{rrccc}\text { High } & 1.23 & (1.18,1.28) & \mathbf{1 . 1 6} & \mathbf{( 1 . 1 1 , 1 . 2 1 )} \\ \text { Middle } & 1.00 & \text { Ref } & 1.00 & \text { Ref } \\ \text { Low } & 0.83 & (0.78,0.87) & \mathbf{0 . 9 1} & \mathbf{( 0 . 8 6 , 0 . 9 6 )}\end{array}$

GSN Apps for Sex

\begin{tabular}{|c|c|c|c|c|}
\hline Never & 0.87 & $(0.80,0.95)$ & 0.91 & $(0.83,0.99)$ \\
\hline Sometimes & 1.00 & Ref & 1.00 & Ref \\
\hline Daily & 1.05 & $(1.01,1.09)$ & 1.02 & $(0.98,1.06)$ \\
\hline \multicolumn{5}{|l|}{ Binge Drinking } \\
\hline No & 1.00 & Ref & 1.00 & Ref \\
\hline Yes & 1.06 & $(1.02,1.11)$ & 0.99 & $(0.95,1.04)$ \\
\hline \multicolumn{5}{|l|}{ Substance Use } \\
\hline No use & 1.00 & Ref & 1.00 & Ref \\
\hline Erectile dysfunction use only & 1.24 & $(1.16,1.32)$ & 1.16 & $(1.08,1.24)$ \\
\hline Marijuana use only & 1.20 & $(1.15,1.25)$ & 1.17 & $(1.12,1.23)$ \\
\hline Marijuana and erectile dysfunction use & 1.42 & $(1.34,1.51)$ & 1.33 & $(1.24,1.42)$ \\
\hline
\end{tabular}

Abbreviations. PrEP= Pre-Exposure Prophylaxis; MSM=Men who have Sex with Men; HIV=Human Immunodeficiency Virus; PR= Prevalence ratios; GSN= Gay Social Networking

*May not add to total because of missing data

adjusted for: age, education, race/ethnicity, income, GSN apps for sex,

binge drinking, substance use 
Page 18/20 
Table 4: PrEP awareness among MSM in Peru, crude and adjusted prevalence ratios $(n=2,150)$ April, 2018

\begin{tabular}{|c|c|c|c|c|}
\hline & \multicolumn{2}{|c|}{ Crude PR } & \multicolumn{2}{|c|}{$\begin{array}{l}\text { Adjusted Model: Peru } \\
\left(\mathrm{n}=1,812^{*}\right)\end{array}$} \\
\hline & Crude PR & $95 \%$ CI & $\begin{array}{c}\text { Adjusted } \\
\text { PR }\end{array}$ & $95 \% \mathrm{CI}$ \\
\hline \multicolumn{5}{|l|}{${ }^{\mathrm{a}}$ MSM Risk Index } \\
\hline Low & 1.00 & Ref & 1.00 & Ref \\
\hline High & 1.03 & $(0.94,1.13)$ & 0.97 & $\begin{array}{l}(0.88 \\
1.07)\end{array}$ \\
\hline \multicolumn{5}{|l|}{ Age, years } \\
\hline $36+$ & 1.57 & $(1.37,1.78)$ & 1.13 & $\begin{array}{l}(0.95 \\
1.33)\end{array}$ \\
\hline $31-35$ & 1.42 & $(1.23,1.65)$ & 1.07 & $\begin{array}{l}(0.91 \\
1.27)\end{array}$ \\
\hline $25-30$ & 1.41 & $(1.26,1.57)$ & 1.14 & $\begin{array}{l}(1.00, \\
1.30)\end{array}$ \\
\hline $18-24$ & 1.00 & Ref & 1.00 & Ref \\
\hline \multicolumn{5}{|l|}{ Education } \\
\hline Postgraduate & 1.76 & $(1.51,2.06)$ & 1.13 & $\begin{array}{l}(0.93 \\
1.38)\end{array}$ \\
\hline Completed undergraduate & 1.49 & $(1.30,1.70)$ & 1.17 & $\begin{array}{l}(0.99 \\
1.38)\end{array}$ \\
\hline Completing undergraduate & 0.99 & $(0.84,1.17)$ & 0.85 & $\begin{array}{l}(0.71 \\
1.03)\end{array}$ \\
\hline High school or less & 1.00 & Ref & 1.00 & Ref \\
\hline \multicolumn{5}{|l|}{ Race } \\
\hline White & 1.00 & Ref & 1.00 & Ref \\
\hline Black & 0.51 & $(0.31,0.86)$ & 0.62 & $\begin{array}{l}(0.38 \\
1.03)\end{array}$ \\
\hline Mix & 0.88 & $(0.79,0.98)$ & 0.90 & $\begin{array}{l}(0.80 \\
1.00)\end{array}$ \\
\hline Other & 0.88 & $(0.67,1.17)$ & 0.85 & $\begin{array}{l}(0.62 \\
1.18)\end{array}$ \\
\hline \multicolumn{5}{|l|}{ Income } \\
\hline High & 1.48 & $(1.34,1.64)$ & 1.33 & $\begin{array}{l}(1.18, \\
1.50)\end{array}$ \\
\hline Middle & 1.00 & Ref & 1.00 & Ref \\
\hline Low & 0.77 & $(0.69,0.87)$ & 0.85 & $\begin{array}{l}(0.74 \\
0.97)\end{array}$ \\
\hline \multicolumn{5}{|l|}{ GSN Apps for Sex } \\
\hline Never & 0.70 & $(0.61,0.82)$ & 0.74 & $\begin{array}{l}(0.63 \\
0.87)\end{array}$ \\
\hline Sometimes & 1.00 & Ref & 1.00 & Ref \\
\hline Daily & 1.10 & $(1.00,1.21)$ & 1.09 & $\begin{array}{l}(0.99, \\
1.20)\end{array}$ \\
\hline \multicolumn{5}{|l|}{ Binge Drinking } \\
\hline No & 1.00 & Ref & 1.00 & Ref \\
\hline Yes & 0.95 & $(0.86,1.05)$ & 0.87 & $\begin{array}{l}(0.79 \\
0.97)\end{array}$ \\
\hline \multicolumn{5}{|l|}{ Substance Use } \\
\hline No use & 1.00 & Ref & 1.00 & Ref \\
\hline Erectile dysfunction use only & 1.29 & $(1.02,1.62)$ & 0.99 & $\begin{array}{l}(0.77 \\
1.28)\end{array}$ \\
\hline Marijuana use only & 1.29 & $(1.17,1.43)$ & 1.35 & $\begin{array}{l}(1.21 \\
1.50)\end{array}$ \\
\hline
\end{tabular}


Abbreviations. PrEP= Pre-Exposure Prophylaxis; MSM=Men who have Sex with Men; HIV=Human Immunodeficiency Virus; PR= Prevalence ratios; GSN= Gay Social Networking

* May not add to total because of missing data

aAdjusted for: age, education, race/ethnicity, income, GSN apps for sex, binge drinking, substance use 